\title{
The Digitizing Research on the Film and TV Arts in New Media Era
}

\author{
Huiqiong Huang ${ }^{1, a}$ \\ ${ }^{1}$ Hankou University, 299 jiangxia district, wuhan, hubei 430212, China \\ ahhq911@foxmail.com
}

Keywords: Film and TV Arts, New Media, Digitizing

\begin{abstract}
New media technology and digital technology will further promote the development of film and TV arts. The new media technology and digital technology provides new creative platform and performance space for film and TV arts and also provides unprecedented experience for viewers. New media technology and digital technology has had a huge impact on creation, distribution, and marketing of visual arts. This paper analyzes the creation, dissemination and marketing of visual arts under the new media age, explores the way of survival and development of visual arts, hoping to bring enlightenment for creation, communication, marketing of visual arts.
\end{abstract}

\section{Introduction}

Cinema is an art and technology mutual integration of modern art, video art is the development of human science and technology continue to use the medium of film and television mode of existence and expression means to expand the process, advanced scientific and technological means to enable the creation of visual arts enrich. It expands the visual arts field spread, so as to enhance the art of film and television industry profits. Discussion on the development of digital television in the new media era of art, film and television creative guidance, the spread of Television Arts and the successful marketing of film and television arts, health watch Television Arts constructive [1].

\section{The Overview of New Media and Digital Technology}

The Brief Introduction of New Media. The new media is driven by global technical reforms to the Internet, mobile communications and other digital communication technology, media platform with innovative capabilities and institutions in the business model, which focuses on covering the digital television technology based on digital television new media such as digital television, digital movies; network technology based broadband network of new media, such as Internet web sites, web logs, network television, Internet broadcasting and others; communication technology-based mobile digital new media, such as building TV, Car TV, mobile TV, outdoor and television. As an integrated, open, changing media, it can also define the concept of new media for the network technology, digital television technology, the use of wireless networks, broadband networks, the Internet, satellite transmission of information, the TV, mobile phones, computers, etc., as an information terminal, the data and other information and entertainment services in the form of digital content as a medium of transmission. Compared with traditional media technology, new media technology for the film and television arts production, dissemination, marketing has injected new elements to make significant changes in the mode of transmission on [2].

The Brief Introduction of Digital Technology. In the computer industry in all the analog information into digital information, that is composed of 0 and 1 binary string, we put this conversion process is called digitization. The digitized information into machine language became, that can be processed by a computer and operate. Digital may also be understood as digital technology to expand to process all aspects of human life. Based on digital technology, new media, the diversion of most of the traditional media audiences, such as a network TV, mobile TV, change the past, sitting in front of the TV to watch film and television work, to attract more audiences. 


\section{The Digitized Creation of Film and TV Arts}

Digital video art refers to a video digital technology with the traditional process of combining video art after the artistic process. Digital technology is video art provides a novel means of creation can effectively improve efficiency and strengthen the aesthetic effect of the image, enhance the creators of creative ideas, be able to bring the audience dreamlike visual experience. Digital technology should permeate every aspect of artistic creation among television, film and television from the preparatory work should begin widespread use until the completion of the creation of film and television works.

The Preparation of Digitizing. Before shooting film and television works of art, preparatory work should be prepared in advance, which will directly determine the artistic achievement and artistic value of film and television works. In playwriting, information collection, production budget, production process based preparatory work can be done by computer. Word processing and script writing software for the creation and modify the script provides a convenient, compared with the earlier creation using pen and paper, which greatly improves the efficiency of the script creation and modification. Lot on location information database, actor databases greatly facilitate the information gathering work crew staff. Professional crew program management software, you can put the device with the cast and crew needed every scenarios were detail-oriented, production costs can be calculated accurately and draw budget, make a complete list of the shooting process. The use of digital technology has brought great convenience to the preparatory work for film and television art [3].

The Live Production of Digitizing. Compared with the figure of the preparatory work, the digital field shooting scene is equally important, computerized equipment management and virtual production is the key to this link. Device management via computer-controlled camera screen capture, and control the lighting apparatus lighting layout, handling all shooting props to complete the scheduled work director. Virtual production technology is based on a chroma key technology and computer graphics, its application is reflected in film and television arts in conjunction with the combination of virtual situations of real people, real situations and virtual characters, the former more used to record TV programs, after those more used in film and television drama filming, the advantage that goes beyond the traditional shooting scene, props, lighting constraints. Computerized equipment management and virtualization technology, not only shorten the working time, avoiding manual error prone, but also improve the efficiency of the shooting, saving manpower, material and financial resources.

The Post-Processing of Digitizing. Post-processing is one of the most influential figures in the film in the process of artistic creation. Digital synthesis technology with digital technology and computer platforms, different screen material synthesized into a single composite picture, the sound and the picture-depth modification and beautification, giving the image a new color. Image overlay can be either a computer image processing, called the dominant synthesis, the purpose is to give the audience a visual shock; the actual screen can also be taken with a video camera, called recessive synthesis, it is to add narration to image elements. Through a series of digitized video art tools to improve the efficiency of the creation of film and television work, and strengthen the aesthetic effect of the arts, to meet the audience's desire for novelty knowledge, enrich the aesthetic experience of the audience.

\section{The Communication of Digitized Film and TV Arts}

Television is an important part of film art communication arts development. Only after the spread of television arts will be able to be appreciated audience, only to realize their artistic value. Digital Television Arts can narrow the distance with the audience, to protect propagation quality visual arts, visual arts broaden the communication platform. Digital media technology created a new communications platform, such as digital TV, Internet TV, the mobile TV and so on. Digital TV technology compared with traditional analog television, it has added many new services, such 
as interactive on-demand, remote education, the TV shopping and bill payment services. Digital TV has a high transmission efficiency, reception good, strong anti-jamming capability, powerful, user-friendly operation, etc., digital television enrich and facilitate people's daily lives, the majority of users. At the same time, with the ever-changing Internet technology and the rapid development of communication technology, from streaming media technology and mobile TV network television began to rise, and gradually deepened people's daily life, its flexible approach and rich content to attract the majority of TV machines in front of the audience [4].

Depending on network television receiving equipment can be divided into a TV set-top box platform based on network TV and network TV-based computer platform, mobile TV is based on the Platform for mobile phone television program reception and playback devices. Web TV and mobile TV not only has a wealth of video resources, but also with video management and search capabilities, user-friendly favorite videos, easy next time continue to watch; with download function, viewers can watch at any time after the download video. Compared with network TV and digital TV, mobile TV has autonomy space, so watching TV is no longer constrained to a closed and static space, but as well as the open environment in the state of sports entertainment experience, the immediate move It is the highlight of the mobile TV.

\section{The Marketing of Digital Film and TV Arts}

In a market-oriented economy mode of operation, both a film and television works of art, is a commodity, present, China's film and television arts industry is in a period of rapid development, along with the development of China's socialist market economy, consumption structure will gradually promotion, video art market demand will be further expanded, video art industry vast potential development space. Digital marketing under the new media age, with the popularity of new media technologies and digital technology and developed. With the rapid development of communication technology and digital technology, the Internet came into being, its development for the dissemination of video art works provide a new platform. After the film and television arts marketing network represents a new direction for the future development of video art, new media technology-based network marketing has become an important means of film and television works issue, a lot of film and television works of art are in the network jump red, was absorbed into the TV station platform play, which not only improves the efficiency of the dissemination of film and television work, also received substantial economic benefits.

Although the network issue is convenient, but BT downloading software release makes the network increasingly serious problem of copyright disputes. Recombinant marketing model that allows a variety of marketing tools and tools combine real-time according to the situation of the implementation of dynamic improvement to solve the current major marketing practices and concepts swap the two sides reached the value added in the interaction is. The important task is to maintain the current copyright interest in film and television arts industry, complete maximize industry profits through the Internet platform.

\section{The Implications and Prospects of Film and TV Technology in the Digital Media Era}

That changed in the twinkling of current technology and cultural environment, people continue to occur for the new changes has been very adapt, almost unthinkingly accept every newly coming things, but continues to accept new things in the exhibit cannot forgive numbness. These performance fanaticism and numbness in people new things and existence value cannot be rational thinking, often behave too emotional.

Technology never has two sides, it is true, screen and digital technologies left us a lot of beautiful images beautifully thrilling, but digitization also brought some new problems for the film and television art. Currently, the use of digital technology to a "technical fetishism," the trend in the film and television art, and the neglect of artistic content only using digital technology, only obsessed with the visual impact fn ignored the story, only the pursuit of scientific and technological content and ignore the ideological implication "two high and one big "that high-tech, high-cost, big 
production of large overwhelming, surface, visual arts market seems to be unprecedented prosperity, but in fact, more works are of poor quality.

New media technologies and the development of digital technology for film and television art had a tremendous influence, video art was the new media technology and digital technology have splendid contrast. At the same time, film and television arts along with the use of new media technology and digital technology to produce the worry and confusion, while cherish the current development of digital media, to promote the vigorous development of visual arts, film and television art is the focus of our staff [5].

At this stage, the development of China's film and television arts compared with developed countries is still in the early-period, we need to attract film and television arts and technology in all aspects of culture, to its dregs, its essence, in order to protect the visual arts flourish. In general, the development of China's film and television art, not only need advanced new media technology and digital technology, high-quality film and television creative artists need more times, but not a lack of tolerance and support from the audience, only perseverance efforts to achieve the development of digital television in the new media arts era.

\section{Conclusions}

In summary, with the advent of the digital media age, the advanced modern technology is widely applied to the creation, dissemination, marketing of visual arts. The majority of the film and television arts staff must abide by the work principle "arts-oriented, technology-use", so that art creation and technology updates can be integrated more organically to enrich creative means of the visual arts by new media technologies and digital technology, extended communication spread of video arts and enhance industrial profit of visual arts.

\section{References}

[1] Yuanyuan Huang: Imaging Technology, Vol. 6 (2004) No 53, p.25-26

[2] Leilei Jia: Filmmaking, Vol. 12 (2005) No 27, p.74-76

[3] Feng Lin: Wuhan University, Vol. 1 (2006) No 33, p.11-14

[4] Jinlin Li: Zhejiang Medial Institute, Vol. 3 (2007) No33, p.121-124

[5] Runsheng Ma: Television Studies, Vol. 3 (2007) No33, p.121-124 